\title{
Severe Multi-inflammatory syndrome in children amidst tropical fevers- an overlapping spectrum, its clinical and laboratory attributes from a tertiary care centre in India.
}

\section{Arpita Chattopadhyay ( $\nabla$ chattopadhyay.arpita@gmail.com )}

Chacha Nehru Bal Chikitsalaya

Karnika Saigal Kalra

Chacha Nehru Bal Chikitsalaya

Diganta Saikia

Chacha Nehru Bal Chikitsalaya

Varshanjali Yadav

Chacha Nehru Bal Chikitsalaya

Juhi Chouksey

Chacha Nehru Bal Chikitsalaya

Mamta Jajoo

Chacha Nehru Bal Chikitsalaya

B L Sherwal

Chacha Nehru Bal Chikitsalaya

\section{Method Article}

Keywords: Multi-inflammatory syndrome in children temporally related to COVID-19 (MISC), Shock, Inflammatory markers, SARSCOV 2 Antibody, myocardial dysfunction

Posted Date: June 2nd, 2021

DOl: https://doi.org/10.21203/rs.3.rs-570509/v1

License: (c) (1) This work is licensed under a Creative Commons Attribution 4.0 International License. Read Full License 


\section{Abstract}

Objective: We aim to describe our experience in terms of clinical and laboratory attributes in children with Multi - inflammatory syndrome in children temporally related to COVID-19 (MISC) presenting amidst other prevalent tropical infections.

Design: Prospective case series.

Setting: A tertiary care hospital pediatric intensive care unit (PICU).

Patients: Seventeen children with severe MIS-C managed in PICU.

Methods: We did a prospective case series of children (aged $\leq 12$ years), admitted to PICU between

May 1, 2020 and January 31, 2021, fulfilling the case definition of MIS-C published by World Health Organization (WHO) or Centers for Disease Control and Prevention (CDC). We analysed routinely collected demographic, clinical, laboratory data and echocardiographic findings. We also plotted the variation in trends between survivors and nonsurvivors.

Results: 17 critically ill children with no previous comorbidities fulfilled the WHO/CDC classification of MIS-C. Median age at admission was 4 years (range 1 y 6 mo-8 years). Fever, rash and conjunctival redness were most prominent symptoms. Myocardial involvement was seen in $70.5 \%$ while $76.4 \%$ developed shock; Invasive mechanical ventilation was required in $64.7 \%$ cases. Inflammation markers were highly raised - median $\mathrm{C}$ - reactive protein $(\mathrm{mg} / \mathrm{L})$ showed serial reduction in levels - from (median/IQR) $210(132.6,246.9)$ at admission to PICU to $52.3(42,120)$ on Day 3. Median Ferritin $(\mathrm{ng} / \mathrm{ml})$ $(\mathrm{n}=12)$ was $690(203,1324)$, serum LDH $(\mathrm{IU} / \mathrm{L})(\mathrm{n}=12)$ was $505(229.5,1032)$ and Mean D-dimer $(\mathrm{ng} / \mathrm{ml})$ $(n=7)$ was 5093.85 (1991.65), suggestive of hyperinflammatory syndrome. Although neutrophilia was seen in 16 patients [Mean (SD) - 14,952.9/ $\mu$ l (7175.2)], lymphopenia was uncommon and seen in only $4 / 17$, median (IQR) [3000/ $\mu \mathrm{l}(2245,4508)] .12$ patients received intravenous immune globulin, with adjunctive steroid therapy used in two third of the cases. Six patients expired.

Conclusions. With our case series we wish to highlight the pattern of clinical and laboratory features in a cohort of severe MISC who were positive for SARSCOV2 antibody. We suggest refining the spectra of phenotypes of MIS-C for tropical countries keeping other exanthematous infections that present with fulminant myocarditis and refractory shock in perspective.

\section{Introduction}

The severe acute respiratory syndrome coronavirus-2 (SARS-CoV-2) pandemic has posed as a challenge to public health globally ever since it first emerged in Wuhan, China in December 2019. The virus was initially described to cause mild to asymptomatic infections in the pediatric age group except in children with underlying co - morbidities. However, from April 2020 onwards, several case series emerged about a mysterious hyperinflammatory syndrome akin to Kawasaki disease, Toxic Shock Syndrome and 
Macrophage Activation syndrome from UK ${ }^{1-3}$, Italy ${ }^{4}, \mathrm{USA}^{5,6}$, France $^{7}$ and India ${ }^{8}$. The affected children had evidence of previous exposure to COVID 19 infection (3-6 weeks back), were premorbidly healthy, of school age to adolescents and presented with fever and predominant gastrointestinal symptoms. These reports prompted societies and public health agencies such as RCPCH (Royal College of Paediatrics and Child Health) ${ }^{9}, \mathrm{WHO}^{10}$ and $\mathrm{CDC}^{11}$ to issue worldwide alerts and surveillance definitions in order to facilitate early detection and management of this post - infectious multi - inflammatory syndrome. These criteria focussed on the early detection of the inflammatory cascade leading to multi -organ failure. However, in tropical countries, in settings where certain rapid diagnostics may not be immediately available - these definitions may be inclusionary of several exanthematous infections with multi organ dysfunction often encountered in these regions.

While the epidemiology of this entity is still evolving, studies till date collectively report $68 \%$ of MIS patients require Intensive care unit admissions, 31\% require ventilation, $4 \%$ need salvage therapy as ECMO and a mortality rate of $1.5 \%^{2-5,12}$. To, the best of our knowledge, data from Asian countries on this aspect is still scarce ${ }^{8,13-15}$. We present here, our case series of 17 critically ill children with severe MISC, all of whom were seropositive for SARSCOV 2 Antibodies. Due to the public health emergency and severe shortage of beds, several ICUs were designated as COVID ICUs. As our ICU was a non-COVID facility, we referred all SARSCOV 2 RTPCR positive cases to COVID designated hospitals and our cohort comprises of severe seropositive MISC only. We describe the clinical, laboratory data and echocardiographic findings and plot the variation in longitudinal trends over first 48 hours among survivors and nonsurvivors.

\section{Methods}

Our PICU is a 12 -bedded unit of a tertiary care children's hospital in Eastern part of New Delhi, the capital of India. All children with Kawasaki like or Dengue like illness or suspected MIS-C, that required intensive care unit admission were evaluated based on the MIS-C diagnostic algorithm currently being followed in our PICU (Flowchart 1). We prospectively collected data of children (aged $\leq 12$ years), admitted to PICU between May 1, 2020 and January 31, 2021, fulfilling the case definition of MIS-C published by World Health Organization (WHO) or Centre for Disease Control (CDC $)^{10,11}$.

\section{Case definitions:}

Kawasaki Disease Criteria:

Fever for 5 days with $\square 4$ of the following 5 typical features define classic KD: (i) conjunctival injection, (ii) rash, (iii) erythema and edema of the hands and feet, (iv) cervical lymphadenopathy, and (v) oral mucosal changes. The diagnosis of incomplete KD includes fever with 2-3 of the typical features ${ }^{16}$.

Toxic Shock Syndrome (TSS): Staphylococcal versus Streptococcal Toxic shock syndrome, with diffuse erythroderma, Hypotension, involvement of two or more organ systems, positive cultures ${ }^{17}$. 
Differential diagnosis with other exanthematous viral infections, clinically was made as shown in flowchart 1.

Acute myocarditis was defined with any of the following- elevated troponin, ST segment elevation or depression on electrocardiogram, low voltage complexes, Gallop rhythm on auscultation with evidence of congestive heart failure ${ }^{12}$ or abnormal echocardiography.

Coronary dilatation was considered if coronary artery z-score between 2.0 and 2.5 and aneurysms in z score above 2.5 .

Shock was defined as tachycardia for age, with arterial systemic hypotension, cold extremity, decrease peripheral pulse, capillary refill time $>3 \mathrm{~s}$, oliguria or arterial blood lactate $>2 \mathrm{mmol} / \mathrm{L}^{18}$.

Pediatric ARDS was defined by using Oxygenation Index ${ }^{19}$ and $\mathrm{P} / \mathrm{F}$ ratio. Oxygenation Index (OI) was calculated: $\mathrm{OI}=\left(\right.$ Mean Airway Pressure $\left.\times \mathrm{FiO}_{2} \times 100\right) / \mathrm{PaO}_{2}$.

$\mathrm{P} / \mathrm{F}$ ratio was defined as ratio of partial pressure of oxygen in arterial blood to fraction of inspired oxygen $\left(\mathrm{PaO}_{2} / \mathrm{FiO}_{2}\right)$. Ol and $\mathrm{P} / \mathrm{F}$ ratio were calculated using arterial blood gas reports.

Vasotrope Inotrope Score (VIS) was calculated as described by Wernovsky ${ }^{20}$. Wernovsky Inotrope score (IS) = Dopamine dose $(\mu \mathrm{g} / \mathrm{kg} / \mathrm{min})+$ Dobutamine dose $(\mu \mathrm{g} / \mathrm{kg} / \mathrm{min})+100 \times$ epinephrine dose $(\mu \mathrm{g} / \mathrm{kg} / \mathrm{min})$.

Vasoactive-inotropic Score $(\mathrm{VIS})^{20}=$ Inotrope Score $+10 \times$ Milrinone dose $(\mu \mathrm{g} / \mathrm{kg} / \mathrm{min})+10,000 \times$ Vasopressin dose $(\mathrm{U} / \mathrm{kg} / \mathrm{min})+100 \times$ Norepinephrine dose $(\mu \mathrm{g} / \mathrm{kg} / \mathrm{min})$.

\section{Statistical Analyses}

Results are reported as numbers and proportions for categorical data and as medians and IQRs /Mean and Standard Deviation for continuous data. Data collection were done in Microsoft Excel 2010 and analysed using Stata 13. Longitudinal data over first 48 hours among survivors and non-survivors were plotted on line graphs using mean (SD) or median (IQR).

Between 1st May, 2020 and 31st January, 2021, 365 patients were admitted to the PICU, out of which ,34 patients were referred with clinical suspicion of MISC. Seventeen cases met criteria for MIS-C as per WHO/CDC Classification of which six patients expired (see Flowchart 2). Majority of MIS-C patients were males (64.7\%). All our patients were SARSCOV 2 antibody positive and SARSCOV2 RT PCR negative. The clinical and demographic variables are shown in Table 1. The median age of the children was 4 years (range between 1 year 6 months to 8 years). All patients were previously healthy with no previous comorbidity. The median duration of symptoms were 7 days (IQR 6, 10). The most common symptom was high grade fever present in all 17 cases followed by rash and conjunctival redness present in 12 (70.6\%) 
cases each. Gastrointestinal symptoms such as diarrhoea and vomiting were present in 8 (47\%) cases whereas abdominal pain was present in $7(41.1 \%)$ cases. Among those patients with shock at anytime during PICU stay $(n=13)$, majority -9 children $(69.2 \%)$ were Kawasaki Disease (KD) phenotype. These 9 children did not meet criteria for classical KD. 
Table 1

Patient characteristics:

\begin{tabular}{|ll|}
\hline Clinical and demographic variables $(\mathbf{n}=\mathbf{1 7})$ & Median (IQR)/ Percentage \\
\hline Age (years) & $4(1.6,8)$ \\
\hline Sex & $11(64.7)$ \\
Male (\%) & $6(35.3)$ \\
Female (\%) & \\
Symptoms - & $7(6,10)$ \\
Duration (days) & $17(100)$ \\
Fever (\%) & $12(70.6)$ \\
Rash (\%) & $12(70.6)$ \\
Conjunctival redness (\%) & $8(47)$ \\
Diarrhea/Vomiting (\%) & $7(41.1)$ \\
Abdominal pain (\%) & $1(5.8)$ \\
Cough (\%) & $4(23.5)$ \\
Lymph node enlargement (\%) & \\
\hline PIM 3, Median (IQR) & $15.6(2.5,32.4)$ \\
\hline PELOD 2 & $6.8(3.8)$ \\
Probability & $0.9(0.9,8.5)$ \\
\hline Mechanical ventilation - Invasive (\%) & $11(64.7)$ \\
Noninvasive ventilation (\%) & $6(35.3)$ \\
\hline Shock & $13(76.4)$ \\
Number of Vasopressors/Inotropes & $2(1,3)$ \\
\hline
\end{tabular}




\begin{tabular}{|ll|}
\hline Clinical and demographic variables $(\mathbf{n}=\mathbf{1 7})$ & Median (IQR)/ Percentage \\
\hline Associated organ dysfunction & $12(70.5)$ \\
Myocardial involvement & $10(58.8)$ \\
Acute Kidney Injury & $9(52.9)$ \\
Encephalopathy & $5(29.4)$ \\
Acute respiratory distress syndrome & $2(11.7)$ \\
Acute liver failure & $3(17.6)$ \\
Seizures & $5(29.4)$ \\
Disseminated Intravascular Coagulation & \\
\hline Number of patients with more than 2 organ dysfunction & $9(52.9)$ \\
\hline Treatment & $17(100)$ \\
Antibiotics & $10(58.2)$ \\
Intravenous immunoglobulin & $12(70.6)$ \\
Steroids & $2(11.7)$ \\
IL - 6 inhibitors (Tocilizumab) & $5(29.4)$ \\
Aspirin & \\
\hline
\end{tabular}

Lab markers (see Table 2): 
Table 2

Lab characteristics

\begin{tabular}{|c|c|}
\hline Variables, $n=17$ & Mean (SD)/ Median (IQR) \\
\hline SARSCOV 2 RT PCR positive & 0 \\
\hline SARSCOV 2 Antibody positive & $17(100 \%)$ \\
\hline $\mathrm{pH}$ & $7.33(0.16)$ \\
\hline At admission & $7.36(0.07)$ \\
\hline $6 \mathrm{hrs}$ & $7.28(0.13)$ \\
\hline $12 \mathrm{hrs}$ & $7.32(0.12)$ \\
\hline \multicolumn{2}{|l|}{$24 \mathrm{hrs}$} \\
\hline Highest lactate (mmol/L) & $3.3(1.4,7.2)$ \\
\hline $\mathrm{Hgb}(\mathrm{gm} / \mathrm{dl})$ & $9.4(1.7)$ \\
\hline At admission & $8.9(1.3)$ \\
\hline \multicolumn{2}{|l|}{$24 \mathrm{hrs}$} \\
\hline Total leukocyte count (/cu.mm) & $14,952.9(7175.2)$ \\
\hline At admission & $14,623.5(6061.8)$ \\
\hline Day 1 & $13,888.2(4164.2)$ \\
\hline Day 2 & $14,961.5(6197.3)$ \\
\hline \multicolumn{2}{|l|}{ Day 3} \\
\hline Absolute Neutrophil count (/cu.mm) & $10,534.1(5956.07)$ \\
\hline At admission & $8952.6(4020.3)$ \\
\hline Day 1 & $8015.4(3054.5)$ \\
\hline Day 2 & $9271.6(5022.02)$ \\
\hline \multicolumn{2}{|l|}{ Day 3} \\
\hline Absolute Lymphocyte counts (/cu.mm) & $3000(2245,4508)$ \\
\hline At admission & $3492(1848,4644)$ \\
\hline Day 1 & 2989(2100, 3996) \\
\hline Day 2 & $3636(2600,6300)$ \\
\hline Day 3 & \\
\hline
\end{tabular}




\begin{tabular}{|ll|}
\hline Variables, $\mathbf{n}=\mathbf{1 7}$ & Mean (SD)/ Median (IQR) \\
\hline Neutrophil/Lymphocyte ratio & $3.26(2.2,4.05)$ \\
At admission & $2.99(1.65,3.57)$ \\
Day 1 & $1.87(1.55,3.21)$ \\
Day 2 & $2.3(1.17,4.55)$ \\
Day 3 & \\
\hline Platelets (/microL) & $11(64.7)$ \\
Thrombocytopenia (\%) & $1,60,000(52,000,2,95,000)$ \\
At admission & $1,20,000(86,000,2,62,000)$ \\
Day 1 & $1,50,000(1,00,000,2,64,000)$ \\
Day 2 & $1,37,000(1,00,000,2,00,000)$ \\
Day 3 & \\
\hline
\end{tabular}

Neutrophilia at admission and then at 48 hours of PICU entry was seen in (12/17, 70.5\%) and (8/17, $47.05 \%)$ respectively. Only 4 (23.5\%) patients had lymphopenia at admission. Neutrophil to lymphocyte ratio (NLR) was more than 5 in $(4 / 17,23.2 \%)$ children with MIS-C. Plotting the trends of laboratory investigations within the first 48 hours of admission among survivors and nonsurvivors (Fig. 1a-c) depicted, higher median LDH $[488.5(349.38,627.61)$ vs $6670(4316.4,17656.81)] \mathrm{IU} / \mathrm{L}$, median creatinine $[0.65(0.41,0.89)$ vs $0.93(0.24,1.62)] \mathrm{mg} / \mathrm{dl}$, median AST $[95.8(14.2,177.5)$ vs $2476.16(232.5$, $5184.8)] \mathrm{IU} / \mathrm{L}$ in nonsurvivors. Children who presented with myocardial dysfunction had higher median Ferritin (ng/ml) [1506.24(230.8, 3243) vs 348.5(176.06)], median CRP (mg/L) [217.6(128.1, 307.1) vs 137.84(378, 237.8)] and median LDH (IU) $[1152.2(441.5,2745.1)$ vs $806.3(47,1565.6)]$ (see Fig. 2). In terms of inflammatory markers (see Table 4 ), median C- reactive protein $(\mathrm{mg} / \mathrm{L}$ ) showed serial reduction in levels - at admission [median/IQR) was $210(132.6,246.9)$ ] whereas at Day 3, it dropped to 52.3 (42, 120). Procalcitonin ( $\mathrm{ng} / \mathrm{ml})$ level (median/IQR) at admission to PICU was $6.35(0.77,50.02)$. Other investigations demonstrated, Ferritin at admission $(n=12)$, (Median, IQR) was $690(203,1324)$, LDH at admission and 48 hours $(n=12)$ (Median, IQR) was $505(229.5,1032)$ and $1391(525,15000)$ respectively. Despite a mean D- dimer $(\mathrm{ng} / \mathrm{ml})(\mathrm{n}=7), 5093.85(1991.65)$ only 5 patients were prescribed Aspirin and none were given anticoagulants, due to high rates of DIC and active mucosal and gastrointestinal bleeding.

Shock characteristics (see Table 3): 
Table 3

Shock characteristics

\begin{tabular}{|ll|}
\hline Shock variables, $\mathbf{n}=13$. & Median (IQR)/ Percentage \\
\hline Kawasaki disease phenotype & $9(69.2)$ \\
\hline Toxic shock syndrome phenotype & $1(7.6)$ \\
\hline Fluid bolus administered & $12(92.3)$ \\
\hline VIS & $23.7(7.06,39.09)$ \\
1 hr of PICU admission & $55.38(20.59,90.17)$ \\
6 hrs of PICU admission & $70.88(31.7,110.02)$ \\
12 hrs of PICU admission & $83.34(36.92,129.76)$ \\
24 hrs of PICU admission & $103.73(32.4,126.19)$ \\
48 hrs of PICU admission & \\
\hline Initial vasopressor at shock onset & Adrenaline $-6(46)$ \\
& Dobutamine $-3(23)$ \\
& Noradrenaline $-4(30.7)$ \\
\hline Lactate (mmol/L) $>2$ & $7(53.8)$ \\
\hline Tachyarrhythmias & $8(61.53)$ \\
\hline VIS: Vasotrope Inotrope Score. & \\
\hline
\end{tabular}


Table 4

Inflammatory markers

\begin{tabular}{|ll|}
\hline Variables & Mean (SD)/Median (IQR) \\
\hline C- reactive protein $(\mathrm{mg} / \mathrm{L})(\mathrm{n}=17)$ & $210(132.6,246.9)$ \\
At admission & $69(28,108.7)$ \\
24 hrs & $39.3(20.8,79)$ \\
48 hrs & $52.3(42,120)$ \\
72 hrs & \\
\hline Albumin $(\mathrm{mg} / \mathrm{dl})(\mathrm{n}=17)$ & $12(70.6)$ \\
\hline Hypoalbuminemia $(\%)$ & $2.66(0.69)$ \\
At admission & $2.54(0.63)$ \\
\hline 24 hrs & $2.73(0.37)$ \\
48 hrs & \\
\hline Pro - calcitonin at admission $(\mathrm{ng} / \mathrm{ml})(\mathrm{n}=8)$ & $6.35(0.77,50.02)$ \\
\hline Ferritin $(\mathrm{ng} / \mathrm{ml})(\mathrm{n}=12)$ & $690(203,1324)$ \\
\hline LDH $(\mathrm{IU})(\mathrm{n}=12)$ & $505(229.5,1032)$ \\
At admission & $533(462,3460)$ \\
\hline 24 hrs & $1391(525,15000)$ \\
\hline 48 hrs & \\
\hline Triglycerides $(\mathrm{mg} / \mathrm{dl})(\mathrm{n}=5)$ & $153(142,189)$ \\
\hline Fibrinogen $(\mathrm{mg} / \mathrm{dl})(\mathrm{n}=7)$ & $227(148,370)$ \\
\hline D- dimer $(\mathrm{ng} / \mathrm{ml})(\mathrm{n}=7)$ & $5093.85(1991.65)$ \\
\hline INR $(\mathrm{n}=10)$ & $0.11(0.03,0.35)$ \\
\hline $\mathrm{LL}-6(\mathrm{pg} / \mathrm{ml})(\mathrm{n}=5)$ & \\
\hline Troponin I $(\mathrm{ng} / \mathrm{ml})(\mathrm{n}=8)$ & \\
\hline
\end{tabular}

13 patients developed shock, median (IQR) number of vasopressors used were 2(1,3). 53.8\% of these shock patients had lactate $>2 \mathrm{mmol} / \mathrm{L}$. 12 patients received fluid boluses, the most common vasopressor used was Adrenaline. Despite rapid escalation of care, median (IQR) VIS progressively increased from 1 hour to 48 hours of PICU admission.

Organ dysfunction: 
Myocardial dysfunction was most frequently encountered (12/17, 70.5\%), followed by acute kidney injury $(10 / 17,58.8 \%)$ and encephalopathy $(9 / 17,52.9 \%)$. Acute respiratory distress syndrome was seen in only $5(29.4 \%)$ cases. $6(35.3 \%)$ cases required noninvasive ventilation whereas invasive mechanical ventilation was required in $11(64.7 \%)$ cases due to respiratory failure. Tachyarrhythmias were seen in 8/17 cases - most common being narrow complex tachycardia, diffuse ST segment changes (ST elevation/depression) followed by low voltage complexes in all leads. Median Troponin I ( $\mathrm{ng} / \mathrm{ml})$ in patients with cardiac dysfunction $(n=8)$ was $0.11(0.03,0.35)$. Echocardiogram was performed in 8 patients with myocardial dysfunction, after stabilisation of acute state - mean ejection fraction was $62.25 \%$ (8.13) and only 1 patient had ejection fraction less than $50 \%$. Median Z scores $(n=6)$ of Left Anterior Descending artery, Right Coronary artery and Left Coronary artery were as - $2.45(1,5.3), 2.69$ $(0.74,7.82)$ and $2.32(1,4.4)$ respectively. Two patients were reported to have left anterior descending coronary artery aneurysms, and 2 children had right coronary artery aneurysm (z score 2.5 or greater).

\section{Treatment.}

13 patients were on vasopressors for shock. 10 (58.2\%) patients of MIS-C were administered Intravenous Immunoglobulin (Ivlg) whereas steroids (intravenous/oral) was given in 12 cases (70.5\%). Aspirin was prescribed in 5 children (29.4\%), while only 2 patients received IL -6 inhibitor (Tocilizumab) [received 2 doses] and both survived.

\section{Discussion}

Here, we elaborate the clinical and laboratory attributes of 17 cases of severe MIS-C, fulfilling WHO/CDC criteria, requiring PICU admission, with no other cause identified as possible etiology. Our findings point towards a heterogenous clinical and laboratory spectrum of this post - infectious hyperinflammatory state.

Most series have reported involvement of older age group (above 6 years) 2,3,4,5,21 in MIS-C as compared to children with Kawasaki Disease (less than 5 years of age) ${ }^{16}$, however, in our case series median age was 4 years ( 1 y 6 months, 8 years). Proportion of children less than 5 years admitted with MISC comprised $59 \%$ of cases (Fig. 3). Dhanalakshmi et al. in a similar case series from Chennai, India reported a median age of 6 years in children diagnosed with PIMS -TS ${ }^{22}$.

Majority of patients in our case- series, fulfilled criteria for incomplete KD with shock with multi - organ dysfunction. Clinical manifestations having an overlap with several tropical infections prevalent at the time such as fever with exanthems like presentation led to exclusion of half of referred cases of MISC (Flowchart 2) (Fig. 4a-c). The commonly encountered infectious pathogens that are endemic to our region such as Dengue fever, Chikungunya fever, Leptospirosis, Complicated malaria, Typhoid fever and Scrub Typhus may often fulfil the diagnostic criteria set by WHO/CDC leading to significant confusion and overdiagnosis. Hence in the absence of any cutoffs of inflammatory markers to define cytokine release syndrome in children - presence of shock (cardiogenic/ vasoplegic) ${ }^{1,3,4}$ with high inflammatory markers 
(eg. CRP, PCT, Ferritin, ESR, Triglycerides, cytokine levels such as IL -1, IL - 6) AND evidence of previous COVID infection or contact with COVID case should point towards MISC. Although larger studies are warranted, the phenotypes described in Western data ${ }^{2,23}$ may need to be conformed based on symptomatology and epidemiology of infections encountered in the Asian countries.

Ahmed et al. in their meta- analyses of 39 studies reported commonest symptoms as fever $(n=662$, $100 \%)$, abdominal pain/diarrhea $(n=488,73.7 \%)$, and vomiting $(n=452,68.3 \%)$ and a lower frequency of conjunctivitis $(n=343,51.8 \%)$ and rash $(n=372,56.2 \%)^{24}$. In our series, $\mathrm{Gl}$ symptoms were present in $47 \%$ cases whereas rash or nonpurulent conjunctival congestion in $70.6 \%$ of cases (Table 2 ). Mamishi et al. from Iran reported a similar proportion of symptoms among their cohort ( 45 children with MIS-C) with fever being the commonest symptom, and equal frequency of children presenting with abdominal pain, rash and conjunctivitis $(51 \%)^{25}$. Higher proportion of patients with mucocutaneous findings as compared to gastro - intestinal symptoms was also reported by Dhanalakshmi et al. in 19 Indian children with MIS$\mathrm{C}^{22}$.

In terms of acute phase reactants, Neutrophilia and high CRP levels were seen $70.6 \%$ of our cases, however, lymphopenia was not very common [only 4/17]. White blood cell counts were increased $[14,952.9 / \mu \mathrm{l}(7175.2)]$ at admission, median lymphocyte counts were much higher $[3000 / \mu \mathrm{l}(2245,4508)]$ than reported by Hoste et al. in their systematic review of 68 records $-\left(831.5 / \mu \mathrm{l}[510-1157.5]^{26}\right.$. We observed higher levels of CRP, Ferritin and LDH at admission in those patients who presented with myocardial dysfunction or with shock versus those without these organ dysfunction (Fig. 4). Though this case series was not sufficiently powered to test significance, similar conclusion was drawn by Adams et al in their retrospective analysis of 1080 patients $^{27}$.

Antibody dependent Enhancement as a consequence of existing SARS-CoV-2-specific antibodies in MIS-C patients promotes viral entry into immune cells and activation of pro-inflammatory cytokines such as TNF and IL-6. This appears to be the most prominent mechanism of immune injury in these patients ${ }^{28,29}$. Hence, immunomodulation and specific cytokine blockade appears to hold promise. We performed IL -6 levels on 5 patients with fulminant myocarditis and refractory shock - median (IQR) 48.41 (pg/ml) $(30.8$, 87.04). It was done in those patients who did not improve on first line management as outlined in Flowchart 1. IL - 6 levels were not repeated after first level and CRP was used to monitor degree of hyper inflammation. We used biologics such as Tocilizumab $(8 \mathrm{mg} / \mathrm{kg})$ in two of these children, both survived. One patient (aged 4 years) showed a rapidly declining trend of CRP from $337 \mathrm{mg} / \mathrm{L}$ to $61.8 \mathrm{mg} / \mathrm{L}$ at 72 hours with a concurrent rise in platelet counts from 52,000/cu.mm to 2,38,000/cu.mm. In the second patient (aged 11 years) with features of fulminant myocarditis - gallop rhythm, persistent ST segment depression, cardiomegaly in chest xray, high oxygenation index $(>15)$ at presentation though inflammatory markers did not decrease, lymphocyte count improved from 1320/cu.mm to 3696/cu.mm at 72 hours - this patient however, presented with fungal balanitis on follow up at 1 month of discharge. 
The mortality in children with COVID infection has been observed to be $0.09 \%{ }^{30}$, while in those with MIS-C it ranges between $1.7-11 \% 2,24,26,31$. Whittaker et al. reported in their study of 58 children, $29(50 \%)$ patients required intensive care unit admission, mechanical ventilation required in $43 \%$ and 1 patient expired $^{2}$. As the mortality of every cohort varies with population characteristics, associated co infections and resource availability - we believe our mortality proportion represents the cohort of seriously ill MISC, compounded by effects of late presentations to health facility [PIM 3 (Median/IQR) 15.6(2.5, 32.4)], mechanical ventilation required in $64.7 \%$ cases, failure of more than two organ systems in 9 (52.9\%) children during PICU stay, shock present in $76.4 \%$ cases \{median (IQR) number of vasopressors/inotropes [2(1,3) ]\} and lack of ECMO services.

\section{Limitations}

We had several limitations, due to transport restrictions imposed during extended periods of lockdown and several hospitals being converted into COVID facilities, many more children presented to us late in disease, thus leading to higher mortality rate in our series. Many cases of cardiogenic shock could not benefit from extracorporeal therapies due to lack of availability of this facility.

\section{Conclusions}

With our case series we wish to highlight the pattern of clinical and laboratory features in a cohort of MISC - seropositive for SARSCOV2 antibody. We suggest refining the spectra of phenotypes of MIS-C for tropical countries keeping other exanthematous infections that present with fulminant myocarditis and refractory shock in perspective. We describe our experience with use of Tocilizumab in two children both of whom survived. It's benefit and early use as a rescue therapy in averting the need for ECMO needs larger studies.

\section{Declarations}

The institutional ethics committee waived ethics committee approval, as it was case series of less than 20 subjects.

\section{Conflict of interest: none}

\section{Funding: none}

Acknowledgement: We wish to thank Prof. Rakesh Lodha, Professor, Division of Pediatric pulmonology and intensive care, All India Institute of Medical Sciences, New Delhi for his valuable inputs in the manuscript and guidance in management.

\section{Abbreviations}

$C D C$ - Centre for Disease Control and Prevention 
COVID 19 - Coronavirus disease of 2019.

MISC - Multi -inflammatory syndrome in Children

SARSCOV 2 - Severe acute respiratory syndrome coronavirus 2

WHO - World Health Organization

\section{References}

1. Riphagen S, Gomez X, Gonzalez-Martinez C, Wilkinson N, Theocharis P. Hyperinflammatory shock in children during COVID-19 pandemic. The Lancet. 2020 May 23;395(10237):1607-8.

2. Whittaker E, Bamford A, Kenny J, Kaforou M, Jones CE, Shah P, et al. Clinical characteristics of 58 children with a pediatric inflammatory multisystem syndrome temporally associated with SARS-CoV-2. JAMA 2020 [Epub ahead of print].

3. Ramcharan T, Nolan O, Lai CY, et al. Paediatric inflammatory multisystem syndrome: temporally associated with SARS-CoV-2 (PIMS-TS): cardiac features, management and short-term outcomes at a UK Tertiary Paediatric Hospital [published online ahead of print, 2020 Jun 12]. Pediatr Cardiol. 2020;1-11. doi:10.1007/s00246-020-02391-2.

4. Verdoni L, Mazza A, Gervasoni A, Martelli L, Ruggeri M, Ciuffreda M, Bonanomi E, D'Antiga L. An outbreak of severe Kawasaki-like disease at the Italian epicentre of the SARS-CoV-2 epidemic: an observational cohort study. The Lancet. 2020 Jun 6;395(10239):1771-8.

5. Feldstein LR, Rose EB, Horwitz SM, et al. Multisystem Inflammatory Syndrome in U.S. Children and Adolescents. N Engl J Med. 2020;383(4):334-346. doi:10.1056/NEJMoa2021680.

6. Dufort EM, Koumans EH, Chow EJ, et al. Multisystem inflammatory syndrome in children in New York State. N Engl J Med 2020;383(4):347-58.

7. European Centre for Disease Prevention and Control. Pediatric inflammatory multisystem syndrome and SARS-CoV-2 infection in children - 15 May 2020. ECDC: Stockholm; 2020.

8. Balasubramanian S, Nagendran TM, Ramachandran B, Ramanan AV. Hyper-inflammatory syndrome in a child with COVID-19 treated successfully with intravenous immunoglobulin and tocilizumab. Indian Pediatr. 2020; S097475591600180.

9. Royal College of Pediatrics and Child Health. Guidance-Pediatric multisystem inflammatory syndrome temporally associated with COVID-19, 2020. Available from:

https://www.rcpch.ac.uk/resources/guidance-pediatric-multisystem-inflammatory-syndrometemporallyassociated-covid-19. Accessed March 24, 2020. 
10. Multisystem inflammatory syndrome in children and adolescents with COVID-19. 15 May 2020 Scientific brief: World Health Organisation. Available from: https://www.who.int/publicationsdetail/multisystem-inflammatory-syndrome-in-children-and adolescents- with-covid-19. Accessed March $22,2021$.

11. Centers for Disease Control and Prevention. Emergency preparedness and response: Health alert network. [May 14, 2020]. Available from: https://emergency.cdc.gov/han/2020/han00432.asp. Accessed March 21, 2021.

12. Radia T, Williams N, Agrawal P, Harman K, Weale J, Cook J, Gupta A. Multi-system inflammatory syndrome in children \& adolescents (MIS-C): A systematic review of clinical features and presentation. Paediatric respiratory reviews. 2020 Aug 11.

13. She J, Liu L, Liu W. COVID-19 epidemic: Disease characteristics in children. J Med Virol. 2020;92(7):747-754.

14. Kim YJ et al. (2020) Defining association between COVID-19 and the multisystem inflammatory syndrome in children through the pandemic. Journal of Korean Medical Science 35, e204.

15. Rauf A et al. (2020) Multisystem inflammatory syndrome with features of atypical Kawasaki disease during COVID-19 pandemic. Indian Journal of Pediatrics 87, 745-747.

16. Diagnosis, treatment, and long-term management of kawasaki disease: a scientific statement for health professionals from the American Heart Association. Circulation 2019;140(5):e181-4. doi: 10.1161/CIR.0000000000000703.

17. Gottlieb M, Long B, Koyfman A. The evaluation and management of toxic shock syndrome in the emergency department: a review of the literature. J Emerg Med 2018;54(6):807-14. doi: 10.1016/j.jemermed.2017.12.048.

18. Surviving sepsis campaign international guidelines for the management of septic shock and sepsisassociated organ dysfunction in children. Intensive Care Med. 2020;46: 10-67.

19. Khemani RG, Smith LS, Zimmerman JJ, et al: for the Pediatric Acute Lung Injury Consensus Conference Pediatric Acute Lung Injury: Definition, Incidence, and Epidemiology. Pediatr Crit Care Med 2015; 16(Suppl 1): S23-S40

20. Wernovsky G, Wypij D, Jonas RA, et al: Postoperative course and hemodynamic profile after the arterial switch operation in neonates and infants. A comparison of low flow cardiopulmonary bypass and circulatory arrest. Circulation 1995; 92:2226-2235.

21. Belhadjer Z, Meot $M$, Bajolle $F$, et al. Acute heart failure in multisystem inflammatory syndrome in children (MIS-C) in the context of global SARS-CoV-2 pandemic. Circulation. 2020; doi:10.1161/CIRCULATIONAHA.120.048360 
22. Dhanalakshmi K, Venkataraman A, Balasubramanian S, Madhusudan M, Amperayani S, Putilibai S, Sadasivam K, Ramachandran B, Ramanan AV. Epidemiological and Clinical Profile of Pediatric inflammatory multisystem syndrome-temporally associated with SARS-CoV-2 (PIMS-TS) in Indian children. Indian pediatrics. 2020 Nov;57(11):1010-4.

23. Godfred-Cato S, Bryant B, Leung J, et al; California MIS-C Response Team. COVID-19-associated multisystem inflammatory syndrome in children: United States, March-July 2020. MMWR Morb Mortal Wkly Rep. 2020;69(32):1074-1080. doi:10.15585/mmwr.mm6932e2

24. Ahmed M, Advani S, Moreira A, Zoretic S, Martinez J, Chorath K, Acosta S, Naqvi R, Burmeister-Morton F, Burmeister F, Tarriela A. Multisystem inflammatory syndrome in children: A systematic review. EClinicalMedicine. 2020 Sep 1;26:100527.

25. Mamishi S et al (2020). Multisystem inflammatory syndrome associated with SARS-CoV-2 infection in 45 children: a first report from Iran. Epidemiology and Infection 148, e196, 1-5. https://doi.org/10.1017/S095026882000196X

26. Hoste, L., Van Paemel, R. \& Haerynck, F. Multisystem inflammatory syndrome in children related to COVID-19: a systematic review. Eur J Pediatr (2021). https://doi.org/10.1007/s00431-021-03993-5

27. Abrams JY, Oster ME, Godfred-Cato SE, Bryant B, Datta SD, Campbell AP, Leung JW, Tsang CA, Pierce TJ, Kennedy JL, Hammett TA. Factors linked to severe outcomes in multisystem inflammatory syndrome in children (MIS-C) in the USA: a retrospective surveillance study. The Lancet Child \& Adolescent Health. 2021 Mar 10.

28. Wan Y, Shang J, Sun S, et al. Molecular mechanism for antibody- dependent enhancement of coronavirus entry. J Virol.2020;94(5):e02015-19.

29. Wang Q, Zhang L, Kuwahara K, Li L, Liu Z, Li T, et al. Immunodominant SARS coronavirus epitopes in humans elicited both enhancing and neutralizing effects on infection in non-human primates. ACS Infect Dis. 2016;2:361 - 76 .

30. Hoang A, Chorath K, Moreira A, et al. COVID-19 in 7780 pediatric patients: a systematic review. EClinicalMedicine 2020. doi: 10.1016/j.eclinm.2020.100433.

31. Rothan HA, Byrareddy SN. The potential threat of multisystem inflammatory syndrome in children during the COVID-19 pandemic. Pediatr. Allergy Immunol.2020;00:1-6. https://doi.org/10.1111/pai.13361

\section{Figures}



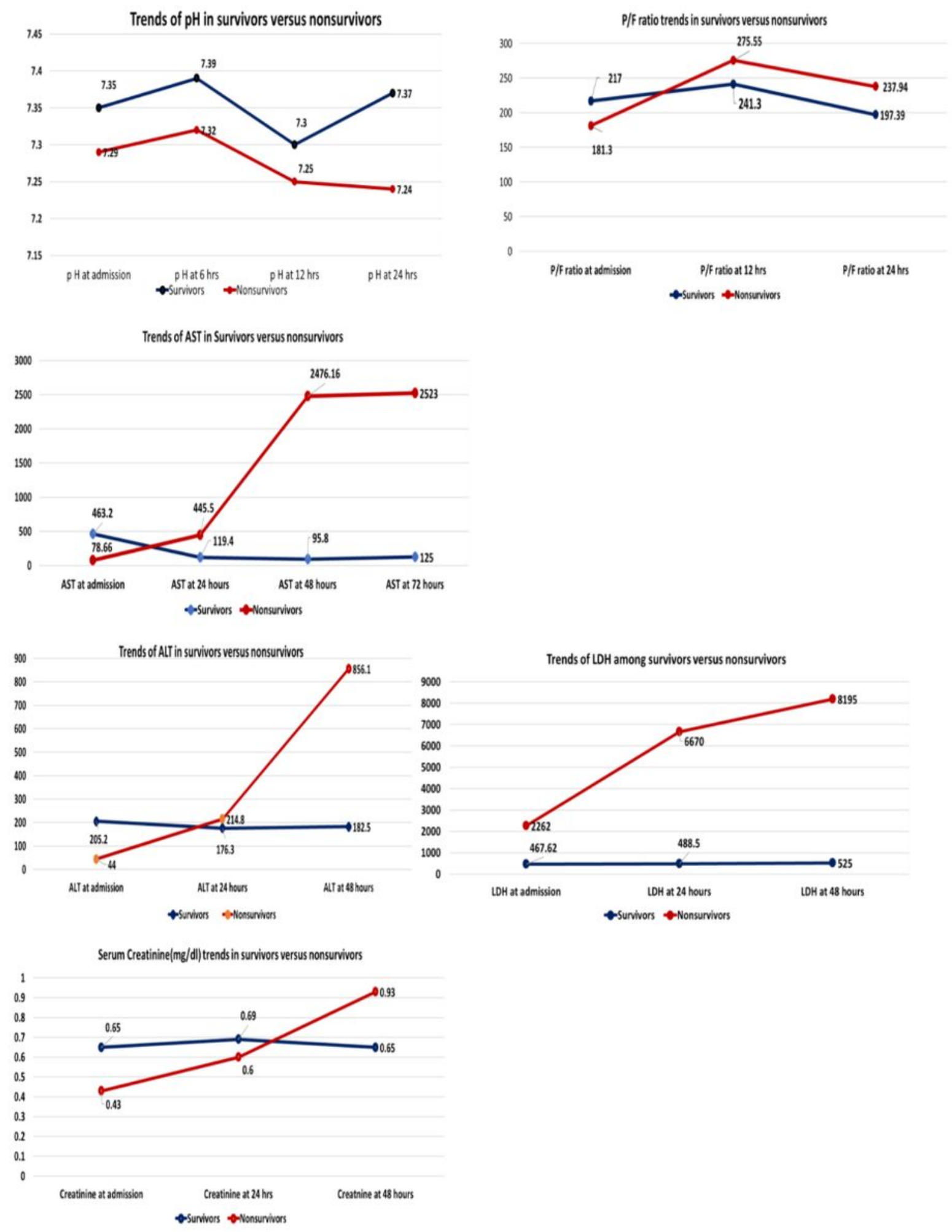

\section{Figure 1}

$a, b, c, d, e, f$ trends of $\mathrm{pH}, \mathrm{PF}$ ratio, AST, ALT, LDH and serum creatinine in survivors versus nonsurvivors. 
Inflammatory markers in those children with shock versus those without.

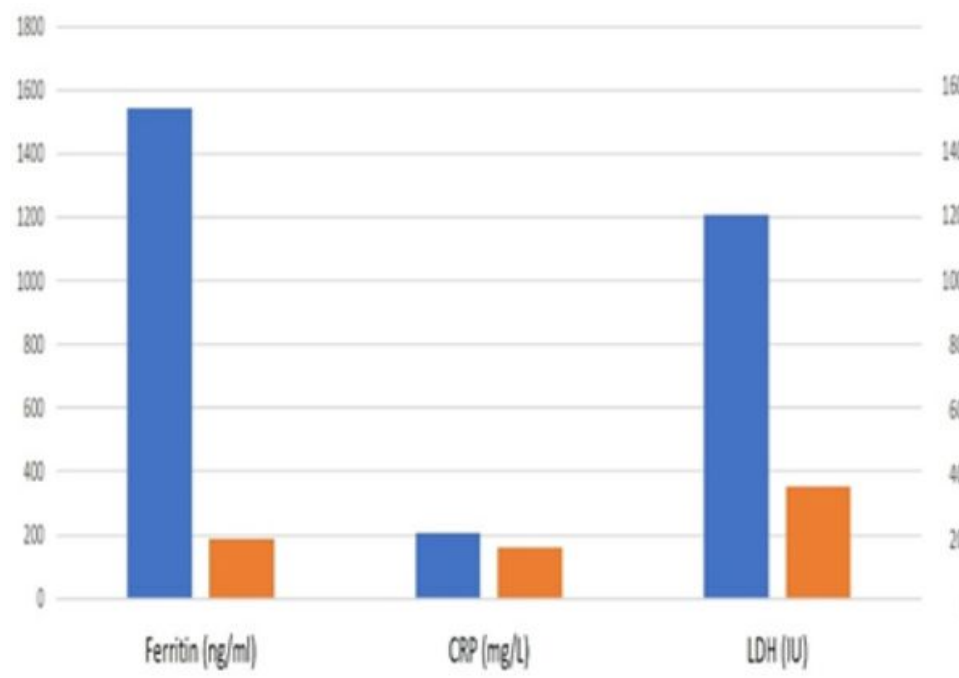

IWth Shock IWithout Shock
Inflammatory markers in those children with myocardial dysfunction versus those without.

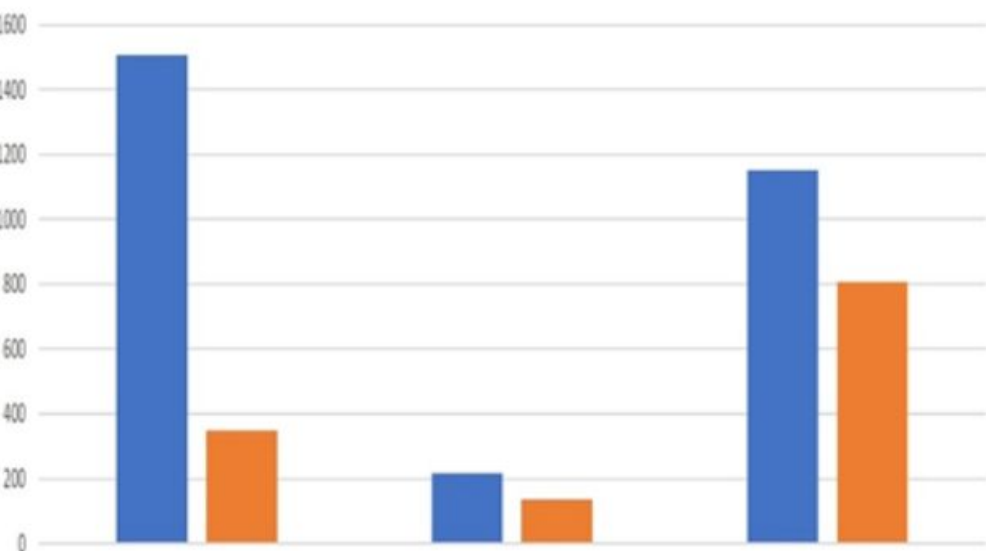

Ferritin $(\mathrm{ng} / \mathrm{m})$
LDH(U)

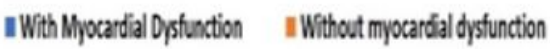

\section{Figure 2}

a,b: Difference in inflammatory markers in those with or without myocardial dysfunction/Those with or without shock

\section{Proportion of different age groups presenting with MISC}

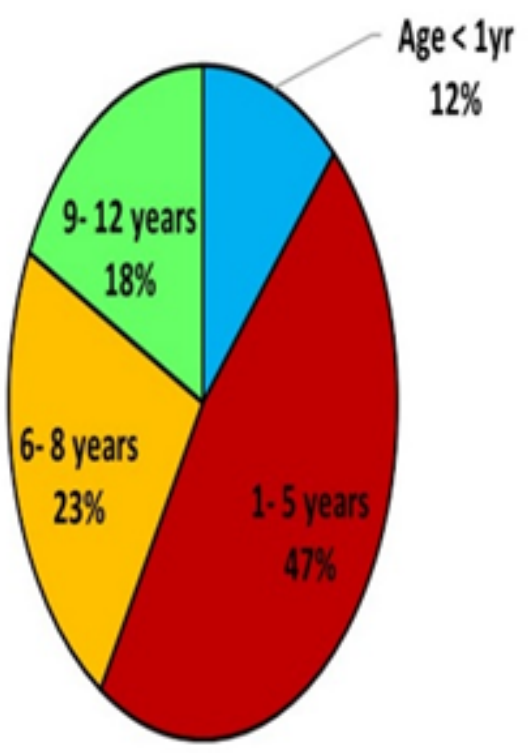

\section{पAge $<1$ yr $\quad \square 1.5$ years $\quad 06.8$ years $\quad \square 9.12$ years}

Figure 3 
(Caption in figure)
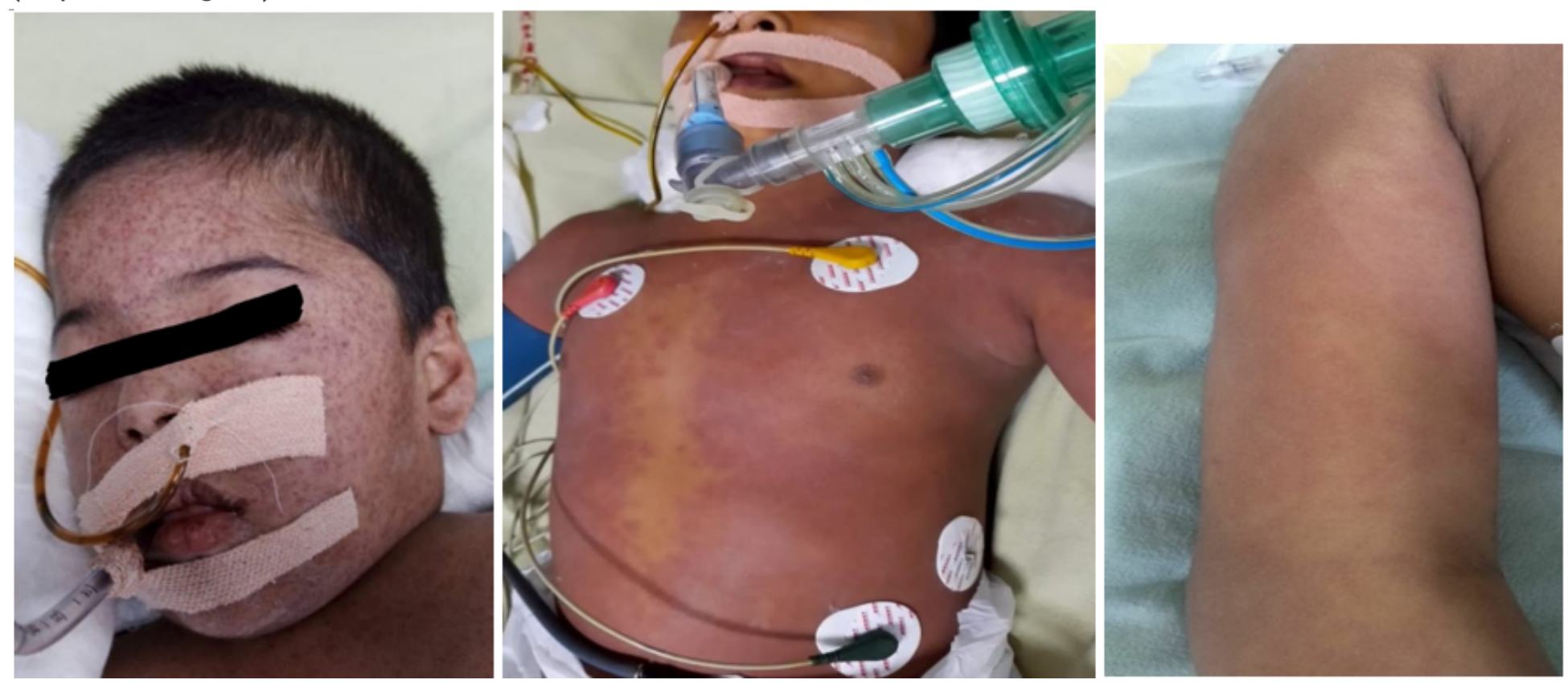

Figure 4

a,b,c: Petechial, maculopapular, generalised rash - varying phenotype of rashes in three patients with severe MIS-C , $a$ and $b$ (nonsurvivors), $c$ (survivor). 


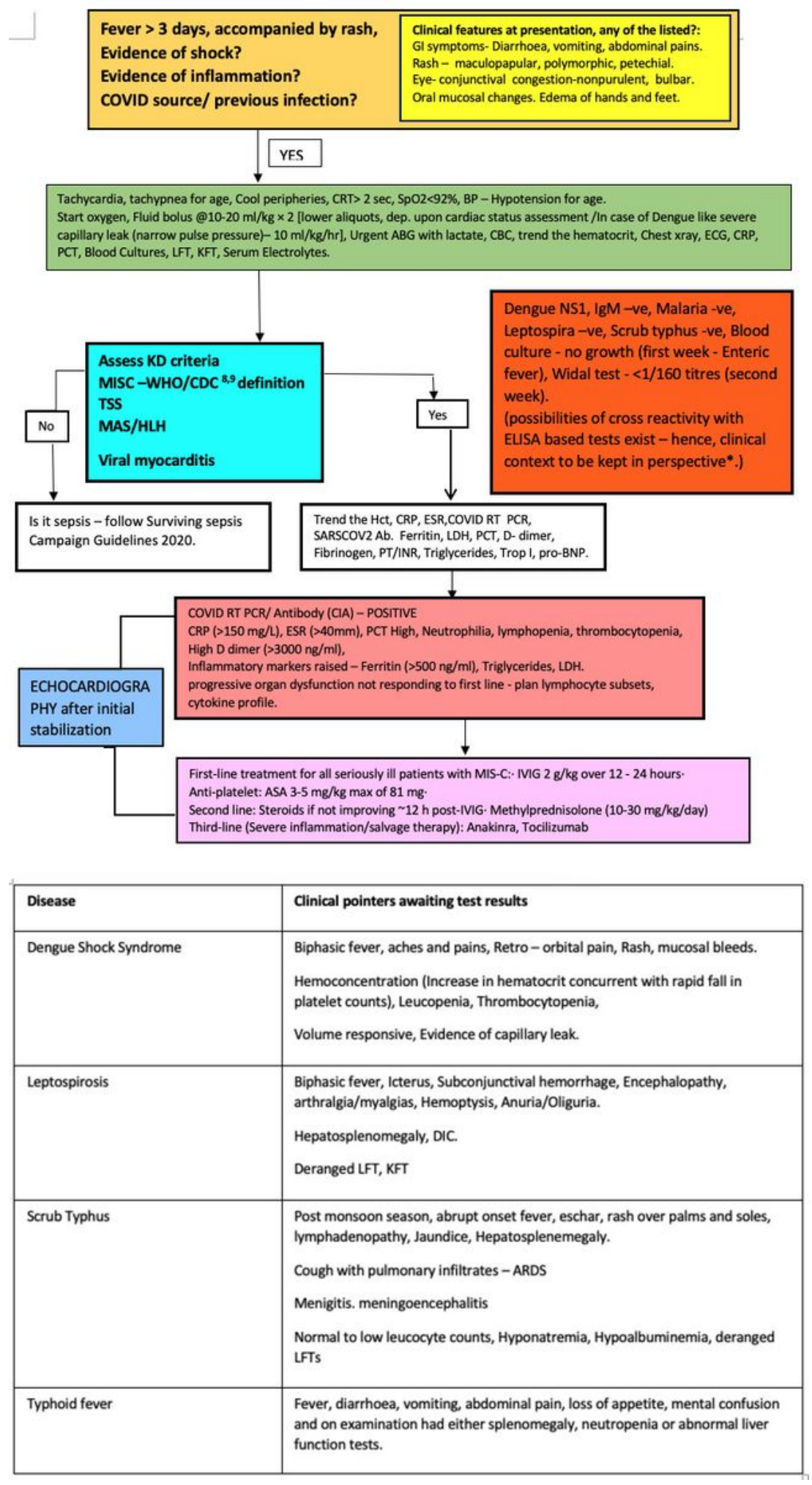

\section{Figure 5}

Flowchart 1: Proposed flowchart as diagnostic and management algorithm followed in Chacha Nehru Bal Chikitsalaya as a management protocol for MISC - at entry to Emergency/ PICU. 


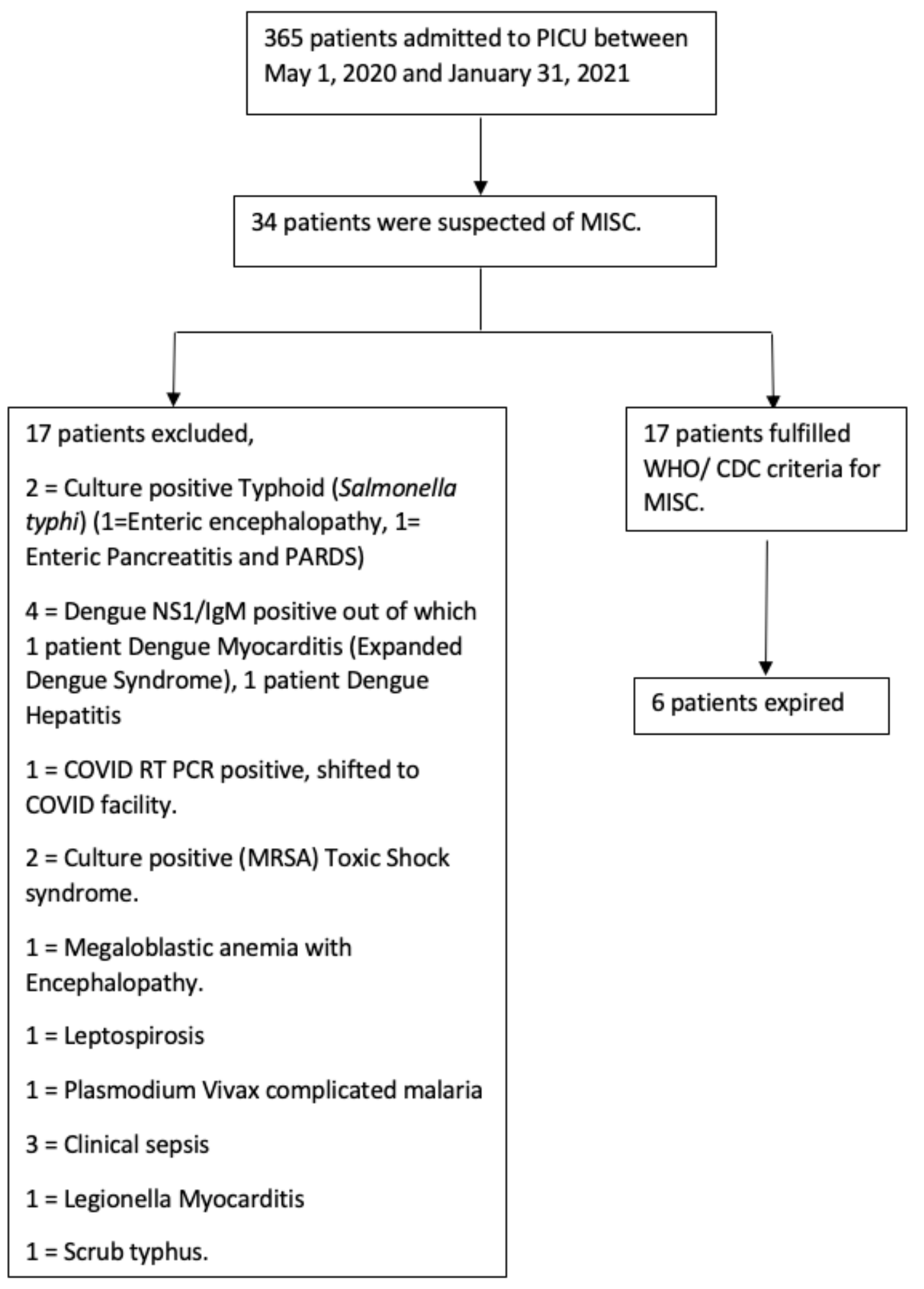

Figure 6

Flowchart 2: Elaboration of cases included and causes of exclusion from final analysis. 